\title{
Torque Quality Improvement of Switched Reluctance Motor Using Ant Colony Algorithm
}

\author{
Fahad Al-Amyal ${ }^{1,2}$, Mahmoud Hamouda ${ }^{1,3}$, László Számel ${ }^{1}$ \\ ${ }^{1}$ Budapest University of Technology and Economics, Department of Electric \\ Power Engineering, Egry József utca 18, H-1111 Budapest, Hungary. \\ ${ }^{2}$ Department of Computer Technical Engineering, College of Technical \\ Engineering, The Islamic University, 54001 Najaf, Iraq \\ ${ }^{3}$ Mansoura University, Electrical Engineering Department, Elgomhouria Street, \\ Mansoura 35516, Egypt \\ E-mail: fahad.alamyal@vet.bme.hu,m_hamouda26@mans.edu.eg, \\ szamel.laszlo@vet.bme.hu
}

\begin{abstract}
The switched reluctance motors (SRMs) are gaining increasing interest in many industrial applications, including electric vehicles (EVs). However, their main drawback is the high torque ripple and noise. This paper presents an optimization-based method to improve the torque quality of SRM drives. The focus is on reducing torque ripple without complicating the control algorithm. The switching angles are optimized using a multistage ant colony algorithm (MSACA). The multistage algorithm provides a better search capability that fits appropriately with the high nonlinearities of SRMs. The finite element method (FEM) is employed to calculate the magnetic characteristics of the tested 8/6 SRM prototype. These characteristics are used within the MATLAB environment in the form of lookup tables to model the machine. The performance indices are calculated within the simulation model. Series of simulation results are included to show the effectiveness of the proposed control. Besides, experimental verification is also included to verify the theoretical findings.
\end{abstract}

Keywords: switched reluctance motor; finite element method; optimization; switching angles; ant colony algorithm

\section{Introduction}

With no windings or magnets on the rotor and concentrated windings on the stator, the switched reluctance motors (SRMs) have the simplest structure of all electrical machines. They can provide reliable, less maintenance, and low-cost variable speed drives. These interesting features made them powerful alternatives to be employed for electric vehicles and the aviation industry [1]-[4]. However, 
the double salient structure makes their magnetic characteristics highly nonlinear functions of rotor position and current. Besides, the inherited torque ripple is the main blocking factor for the acceptance of SRM drives in high-performance applications.

Many strategies have been carried out to reduce the torque ripple of SRMs. They can be classified into two categories: machine design optimization and the other based on control algorithms. Although the design optimization of SRM, such as geometry-optimization, multiphase-machine, and winding configuration, can reduce torque ripple [2]-[3], but after the machine has been manufactured, it is difficult and complicated to modify its geometric dimensions. The alternative way to improve the torque quality of an existing machine is by using advanced control techniques [4]-[9]. Noting that the more complicated the algorithms are, the highcost and low-performance the drive is. Therefore, a trade-off should be adopted to have the best overall performance. A simple control method is the best to be chosen. Hence, further improvements have to be proposed for torque ripple reduction.

The control parameters for SRMs involve the switch-on $\left(\theta_{\text {on }}\right)$, switch-off $\left(\theta_{\text {off }}\right)$ angles, and reference current $\left(i_{r e f}\right)$. The reference current is defined by the outer loop control. Therefore, the switching angles $\left(\theta_{\text {on }}, \theta_{\text {off }}\right)$ are the dominant parameters for SRM control [10]-[13]. Proper estimation of $\theta_{\text {on }}$ and $\theta_{\text {off }}$ must be done accordingly with motor speed and loading torque. This is a very complicated task due to the highly nonlinear characteristics of SRMs. In [14], the switching angles are employed to reduce torque ripple and improve drive efficiency. Online tuning of turn-on angle is proposed, while from the flux linkage waveforms of two neighboring phases, a mathematical formula for the optimal turn-off angle is achieved. This method does not fit for traction application as the operating point is continuously changing. Besides, the formulation uses the linear inductance profile that fits a limited speed range. In [15], efficiency optimization is achieved in steady-state operation by the fine-tuning of firing angles through an algorithm that minimizes the drive's input power. In [16], an online optimization scheme is introduced to determines the optimal turn-on and turn-off angles to provide maximum efficiency. In [17], automatic control of the turn-off angle is presented in the face of automatic turn-on angle control, aiming to maximize the torque per ampere ratio. In [18], The effects of the switch-on and switch-off angles on motor torque, copper loss, and torque ripple are investigated, and a multi-objective function is developed to maximize the average output torque, average torque per RMS value of the phase current, and torque smoothness factor. In [19], analytical formulations are developed for both the switch-on and switch-off angles based on the fitting of phase inductance over the minimum inductance zone. In [20], closedloop control is introduced for the switch-on angle aiming basically to reduce torque ripples and copper losses. First, closed-loop control is proposed for the optimum switch-on angle. Then, the switch-off angle is optimized using a onedimensional search algorithm. In [5], a simple structure average torque control is 
introduced. The switching angles are defined based on a described searching algorithm. The algorithm uses a fixed step resolution that does not guarantee the best outcome. In [21], the switching angles are optimized mainly for torque production improvement, ignoring the generated torque ripple. For EV applications, there are basic requirements that have to be fulfilled by any drive system. These requirements include the minimum torque ripple, especially at low speeds. Besides, minimum losses and high efficiency are also of great interest. Therefore, this paper focuses on achieving the vehicle requirements based on the SRM drive. The focus is to achieve the minimum torque ripple, minimum losses, and maximum drive efficiency. Hence, a trade-off is done to achieve this goal. A modified version of the Ant Colony Algorithm (ACA), called Multistage Ant Colony Algorithm (MSACA), is introduced and implemented to optimize the switching angles. The modification is achieved to fit appropriately with the high nonlinearity in magnetic characterestics of SRMs. The objective is to maximize the average torque (means maximum efficiency), minimize net torque ripple (means minimum torque ripples), and minimize copper losses simultaneously. A simple control algorithm is adopted. Besides, a high-fidelity machine model is built and employed within the optimization problem using the finite element method (FEM). This paper is organized as follows: Section II includes machine modeling. Section III involves the formulation of the optimization problem and the proposed MSACA. Also, the simulation and the experimental results are presented in Sections IV and V, respectively. Lastly, the conclusions.

\section{Machine Modelling}

Due to the doubly salient structure of SRMs, their magnetic characteristics are functions of both the current $(i)$ and the rotor position $(\theta)$. The voltage and torque equations are given by equations (1) and (2), respectively [1].

$$
\begin{gathered}
V=i R+\frac{d \lambda(i, \theta)}{d t}, \quad \therefore \lambda(i, \theta)=\int(V-i R) d t \\
T=\frac{1}{2} i^{2} \frac{d L(i, \theta)}{d \theta}
\end{gathered}
$$

where $V$ is the phase voltage, $R$ is the phase resistance. $\lambda(i, \theta)$ is the flux linkage. $L(i, \theta)$ is the phase inductance.

As the analytical model [22]-[24] does not provide an efficient representation of machine characteristics, the FEM is employed to accurately model the highly nonlinear magnetic characteristics of the tested 8/6 SRM prototype. The dimensional parameters of SRM are given in Table 1. The FEM obtained torque, flux-linkage, and inductance characteristics of the SRM are presented in Figure 1. For verification purposes, these data are presented along with their 
corresponding experimentally measured data. As seen, an excellent agreement is observed, and therefore, the FEM-calculated can be adopted to build a trusted SRM simulation model.

Table 1

The design data of 8/6 SRM

\begin{tabular}{|l|l|l|l|}
\hline Parameter & Value & Parameter & Value \\
\hline Stator/ Rotor poles & $8 / 6$ & Stator outer diameter & $179.5 \mathrm{~mm}$ \\
\hline Number of phases & 4 & Shaft / Bore diameters & $36 / 96.7 \mathrm{~mm}$ \\
\hline Phase resistance & $0.642 \Omega$ & Rotor/stator pole arc & $21.5^{\circ} / 20.45^{\circ}$ \\
\hline Output power & $4 \mathrm{~kW}$ & Height of rotor/stator pole & $18.1 / 29.3 \mathrm{~mm}$ \\
\hline Rated speed & $1500 \mathrm{rpm}$ & Air-gap length & $0.4 \mathrm{~mm}$ \\
\hline Turns per pole & 88 & Stack length & $151 \mathrm{~mm}$ \\
\hline
\end{tabular}

The measurement is done first by applying a pulsed DC voltage to one phase winding of SRM at a known rotor position $(\theta)$. Then, the phase voltage and current are measured and recorded to calculate the phase flux linkage using equation (3) [25].

$$
\lambda(i, \theta)=\int\left(v_{p h}-R i_{p h}\right) d t
$$

where $v_{p h}, i_{p h}$, and $R$ are the phase-voltage, phase-current, and phase-resistance, respectively. $\lambda(i, \theta)$ is the calculated flux-linkage.

The torque is measured directly by the torque transducer. The measurement procedure is repeated several times at different rotor positions.

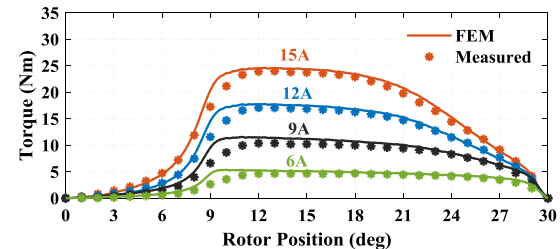

(a) The torque characteristics $\mathrm{T}(\mathrm{i}, \theta)$

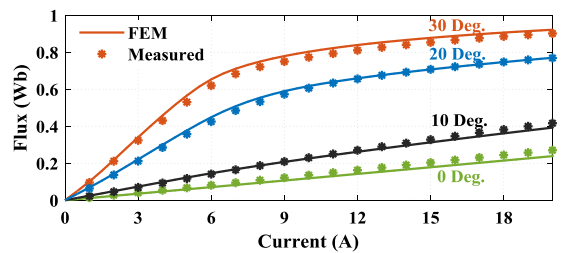

(b) The flux-linkage characteristics $\lambda(i, \theta)$

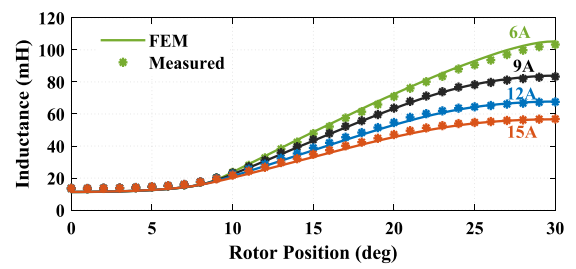

(b) The inductance curves $L(i, \theta)$

Figure 1

The FEM-calculated and the corresponding measured magnetic characteristics 
The complete, steady-state model of one phase of SRM is shown in Figure 2. The inputs are the reference current, motor speed, and switching angles. The outputs are the phase current and torque. A hysteresis controller is used to control the phase current.

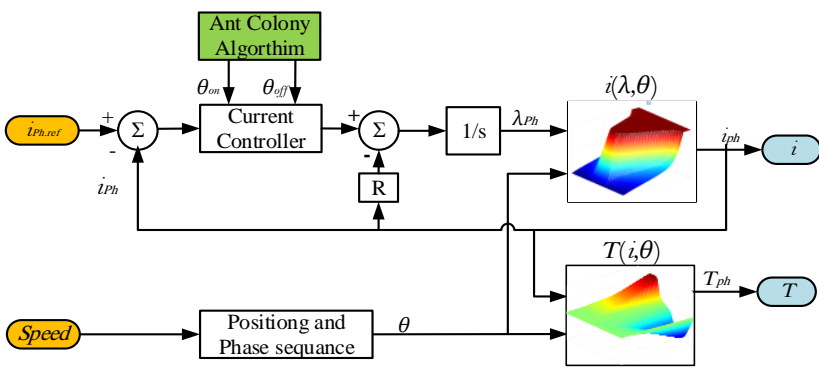

Figure 2

One phase model of $8 / 6$ switched reluctance motor

The performance indices are estimated within the simulation model. They involve the average torque $\left(T_{a v}\right)$, torque ripple $\left(T_{r}\right)$, average supply current $\left(I_{a v}\right)$, root mean square of supply current $\left(I_{R M S}\right)$, and efficiency $(\eta)$. These indices are calculated as follows:

$$
\begin{aligned}
& T_{a v}=\frac{1}{\tau} \int_{0}^{\tau} T_{e}(t) d t \\
& T_{r}=\frac{T_{\text {max }}-T_{\text {min }}}{T_{a v}} \\
& I_{a v}=\frac{1}{\tau} \int_{0}^{\tau} i_{s}(t) d t \\
& I_{R M S}=\sqrt{\frac{1}{\tau} \int_{0}^{\tau} i^{2}(t) d t} \\
& \eta=\frac{\omega T_{a v}}{V_{D C} I_{a v}}
\end{aligned}
$$

where $\tau$ is the time of one electric cycle, $T_{\max }$ and $T_{\min }$ are the maximum and minimum values of instantaneous torque. $i_{s}$ is the instantaneous supply current. $\omega$ is the motor speed.

\section{The Optimization Problem}

The optimization problem consists of two control variables, a multi-objective function, and two constraints. The SRM Simulink model in Figure 2 will be utilized within the optimization problem. Where, after specifying the desired input speed and current, the remaining inputs are the switch-on, and the switch-off 
angles will be considered as the control variables of the optimization problem. On the other hand, from the output torque and current waveform of the Simulink model, the performance indices in (4), (5), and (7) can be calculated. The proposed objective function combines two criteria: the average output torque (4) and the net torque ripple (5). A maximum allowed RMS value of the phase current (7) is specified as a constraint in this problem in order to maintain the motor efficiency with an acceptable range. The upper and lower boundary of the conduction angle is also constrained because, in 8/6 SRM, each phase should contact at least $15^{\circ}$.

Furthermore, a too wide a conduction angle may result in a considerable amount of negative torque generation. The focus is to locate optimal switch-on and switch-off angles to make the motor generate the highest possible average output torque with the minimum torque ripple at each operating point of the torque/speed profile. And therefore, improve the torque quality of the machine in a wide speed range.

\subsection{Problem Formulation}

The formulation of the optimization problem is as shown:

Find the best value of the control variables: $\theta_{\text {on }}$ and $\theta_{\text {off }}$

In order to:

Maximize: $F_{o b j}=T_{a v e}-w\left(T_{\max }-T_{\min }\right)$

subjected to

$\left[\begin{array}{cc}1 & -1 \\ -1 & 1\end{array}\right]\left[\begin{array}{c}\theta_{\text {on }} \\ \theta_{\text {off }}\end{array}\right] \leq\left[\begin{array}{c}-\frac{60^{\circ}}{m} \\ \frac{60^{\circ} K}{m}\end{array}\right]$

$I_{R M S} \leq \max \left(I_{\mathrm{RMS}}\right)$

where $F_{o b j}$ is the proposed objective function, $T_{a v}$ is the average torque (4). $w$ is a constant weighting factor used to magnify the net torque ripple value $\left(T_{\max }-T_{\min }\right)$. $m$ is the number of phases, which is four in our case, and $60^{\circ}$ mechanical degree corresponds to a complete $360^{\circ}$ electrical cycle, $K$ is a constant between ( 1 and $1.85)$ for adjusting the upper boundary of the conduction angle $\left(\theta_{\text {off }}-\theta_{\text {on }}\right)$, different values of $K$ are used at different operating points.

Generally, many algorithms have been presented and carried out by previous researchers to solve optimization problems in different fields of study. These algorithms can be categorized as conventional or meta-heuristics algorithms. The traditional algorithms like the interior point method, newton-raphson method, linear programming, or lambda iterations are complex and require high-level mathematical formulations, especially if the optimization problems are highly 
nonlinear. On the other hand, the meta-heuristics algorithms are inspired by nature and considered powerful tools to solve multi-objective optimization problems. Among these algorithms: the genetic algorithm (GA), particle swarm optimization (PSO), migration algorithm (MA), grey wolf optimizer (GOA), hybrid swarm algorithm, conflict monitoring optimization, slime mold algorithm (SMA), and the ant colony algorithm (ACA) [26]-[32]. These algorithms are easier to implement than the conventional analytical-based techniques and have given very good results over the years. In this paper, a modified version of the ACA is adopted to solve our problem since it can provide outstanding solution quality with short computational time and guaranteed convergence. However, in ACA, the convergence time is uncertain, but since the optimization results are obtained offline, the convergence time does not matter. The ACA and the modified MSACA are illustrated in the following sections.

\subsection{Ant Colony Algorithm (ACA)}

Regardless of their members' simplicity, ant colonies are exceptionally cooperative societies that can accomplish challenging tasks that are long way past single ant capacities [33]. The ACA is influenced by the cooperative methodology of the actual ant colonies, where a kind of indirect contact helps them to find the best path from the home to any food source. The ACA method can be exhibited by the guide of the graph that appeared in Figure 3.

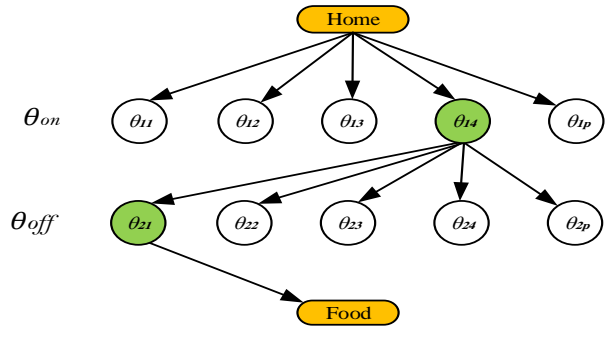

Figure 3

Graphical representation for the ACA

Every raw in the graph corresponds to a controlled variable within the optimization problem. In our case, the first raw corresponds to the switch-on angle while the second raw corresponds to the switch-off angle. In each raw, there are a set of random values within the allowed domain of the control variables called nodes or particles ( $p$ or $\theta_{i j}$ ). Various $N$ ants in the colony will begin looking for food starting from home, traveling via all rows until they arrive at the food source. Through its journey, each ant selects only one particle among the $\theta_{i j}$ particle from each row. The group of particles that each ant has selected will represent a single path or a candidate solution, such as the green path $\left(\theta_{14}, \theta_{21}\right)$. And therefore, at each journey (iteration), the number of candidate solutions equal to the number of 
ants in the colony. Once each journey is finished, every ant store an amount of pheromone on the pre-selected path. The quantity of the stored pheromone is proportional to the preference of the corresponding path. In other meaning, if the selected path gives a better value of the proposed objective function (9), then the ant will store a higher amount of pheromone on that path and vice versa. Whenever the ants return to the food source and start searching again for food, the stored pheromone at each particle will be updated, either increased for particles that are frequently selected by the ants, or evaporated by pre-defined rate from the particles belonging to unvisited paths. Consequently, the probability of these particles being chosen by the approaching ants will increment or decrement relying upon the stored pheromone. In the end, the set of particles stored the largest pheromone amount is nothing but the optimal solution. In contrast, the pheromone of other particles will be totally evaporated. The optimization process will be terminated either if all ants select the same path or the maximum allowed iterations number is reached. In this work, a modified version of the ACA is employed.

\subsection{Multistage Ant Colony Algorithm (MSACA)}

A large number of particles $(p)$ is essential to make a precise selection of the switching angles. However, increasing $p$ will badly affect the search capability of the ACA. Because before the start of the iteration cycle, all particles share the same stored amount of pheromone and, therefore, an equal selection probability. As a result, the chance of choosing the optimal particle amongst a large number of particles will decrease, and due to the evaporation rate of the pheromone, the probability of selecting the optimal solution will further decrease during the optimization procedures, consequently, in some cases, the ants will probably fail to find the optimal solution. Since an accurate selection of the optimal switching angles is the main goal of this paper, a modified version of the ant colony algorithm is necessary. In this version, the simple ACA is repeated in two completely separated stages. In the first stage, the algorithm uses zones $(Z)$ rather than discrete particles $(p)$. After locating the optimal zones for the switch-on and switch-off angles in the first stage, the ACA will search only around and within these zones in the second stage to find a more accurate solution. The idea is to eliminate the need for a higher number of $p$ by narrowing the search domain in the second stage. Figure $4(a, b)$ shows the graphs of the first and second stages of the proposed multistage ant colony algorithm (MSACA). More stages can be used to give higher accuracy. However, the converged time will increase. The proposed MSACA is used in [34] to solve an Economic Emission Dispatch (EED) with six control variables. The results obtained in [34] compared favorably with corresponding results obtained from the GA. 


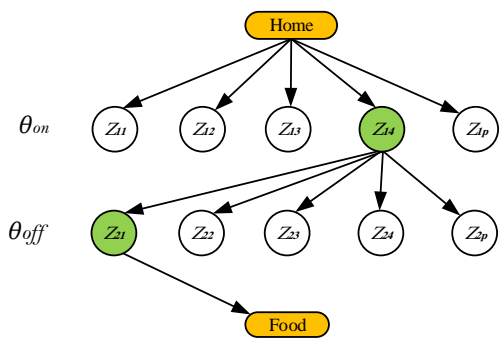

(a) Graph representing the $1^{\text {st }}$ stage

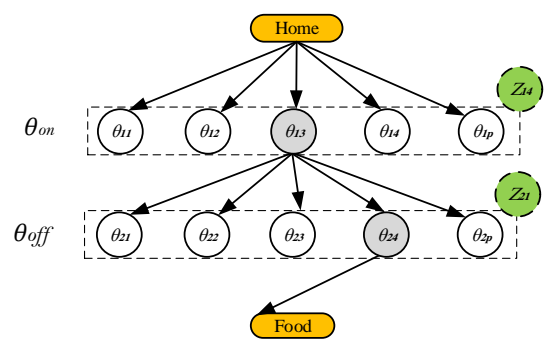

(b) Graph representing the $2^{\text {nd }}$ stage

Figure 4

Graphical representation for the MSACA

\subsection{The Solution Scenario}

The detailed optimization procedures are illustrated in the following steps:

Step 0. Input the desired speed and current commands to the SRM Simulink model and specify the search limit of the switching angles as shown in (12).

Limits $=\left[\begin{array}{cc}\theta_{\text {on_min }} & \theta_{\text {on_max }} \\ \theta_{\text {off_min }} & \theta_{\text {off_max }}\end{array}\right]$

Step 1. Initiate the MSACA parameters: number of ants $(N)$, number of particles $(p)$, pheromone evaporation rate $(\rho)$, number of stages of the MSACA, and the number of allowed iterations in each stage.

Step 2. Start the first stage of the MSACA and formulate the search domain as in figure 3 , within limits specified in step 0 .

Search domain $=\left[\begin{array}{ccccc}\theta_{\text {on_min }} & \theta_{12} & \theta_{13} & \ldots \ldots \ldots & \theta_{\text {on_max }} \\ \theta_{\text {off_min }} & \theta_{21} & \theta_{31} & \ldots \ldots \ldots & \theta_{\text {off_max }}\end{array}\right]_{2 \times p}$

Step 3. Initiate an equal amount of pheromone $\left(\mathcal{F}_{i j}\right)$ in all the $\theta_{i j}$ particles.

Pheromone $=\left[\begin{array}{ccccc}\mathcal{F}_{11} & \mathcal{F}_{12} & \mathcal{F}_{13} & \ldots \ldots \ldots & \mathcal{F}_{1 p} \\ \mathcal{F}_{21} & \mathcal{F}_{22} & \mathcal{F}_{23} & \ldots \ldots \ldots & \mathcal{F}_{2 p}\end{array}\right]_{2 \times p}$

Step 4. Calculate selection probability of each particle $\left(P_{i j}\right)$ using (15)

$P_{i j}=\frac{\mathcal{F}_{i j}}{\sum_{j=1}^{p} \mathcal{F}_{i j}} \quad\left\{\begin{array}{c}i=1: \text { number of control variables } \\ j=1: \text { number of particles }\end{array}\right.$

Step 5. Perform roulette wheel selection process for each ant, so that each ant selects only one particle from each raw of the search domain, for example, ant number $1\left(N^{1}\right)$ select $\theta_{17}$ from the first raw and $\theta_{23}$ from the second raw. Save all selected solutions by each ant, as shown in Table 2 . 
Table 2

Random candidate solutions performed by the ACA

\begin{tabular}{|l|c|c|c|c|c|c|c|}
\hline Ant number & $N^{1}$ & $N^{2}$ & $N^{3}$ & $N^{4}$ & $N^{5}$ & $\ldots \ldots \ldots \ldots$ & $N^{N}$ \\
\hline Selected $\theta_{\text {on }}$ & $\theta_{17}$ & $\theta_{16}$ & $\theta_{11}$ & $\theta_{13}$ & $\theta_{15}$ & $\ldots \ldots \ldots \ldots$ & $\theta_{12}$ \\
\hline Selected $\theta_{\text {off }}$ & $\theta_{23}$ & $\theta_{21}$ & $\theta_{29}$ & $\theta_{28}$ & $\theta_{24}$ & $\ldots \ldots \ldots \ldots$ & $\theta_{17}$ \\
\hline
\end{tabular}

Step 6. Run the Simulink model in Figure 2 for each of the above columns and obtain and save the output torque and current waveforms for each ant.

Step 7. From the stored torque and current waveform, calculate the phase current's RMS value (7), the average torque (4), the maximum and minimum value of the output torque. Check the constraint in (11) and obtain the objective function value from (9).

Step 8. Mark the ant that gave the best objective function value as $N^{\text {best }}$ and update the pheromone $\left(\mathcal{F}_{i j}\right)$ in all particles using (16)

$\mathcal{F}^{\text {new }}{ }_{i j}=\left\{\begin{array}{l}\mathcal{F}^{\text {old }}{ }_{i j} \times 2 \quad \text { for particles belong to } N^{\text {best }} \\ \mathcal{F}^{\text {old }}{ }_{i j} \times(1-\rho) \quad \text { for other particles }\end{array}\right.$

The pheromone evaporation rate $\rho$ has been chosen between ( 0.7 and 0.9$)$ in this work.

Step 9. Check if all ants selected the same solution, then terminate the first stage of the MSACA and go to step 10. If not, repeat from step 4 until the maximum iteration number has been reached.

Step 10. Mark the optimal results of the first stage as $\theta^{\text {best }}{ }_{\text {on }}$ and $\theta_{\text {best }}^{\text {be }}$ and formulate a new smaller domain around these results by updating the old searching limits as shown in (17)

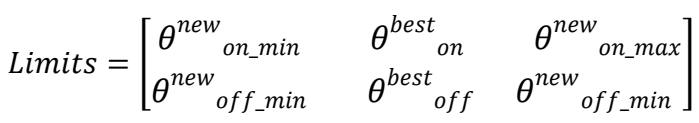

The new minimum and maximum limits in the above search domain are the left and right neighbors of the best particles in the old search domain. In this way, the search space becomes smaller, and the results will be more accurate. Repeat the ACA and search within the new domain by starting from step 3 all the way to step 9.

In this work, the number of ants has been chosen in the range (25-30 ants) while the number of particles in the range (7-11 particles). Two or three stages are adopted. Figure 5 shows the optimized switch-on and switch-off angles for each combination of speed and reference current. As noted in Figure 5 (b), the switchoff angles have a small band of variation compared to the switch-on angles. 


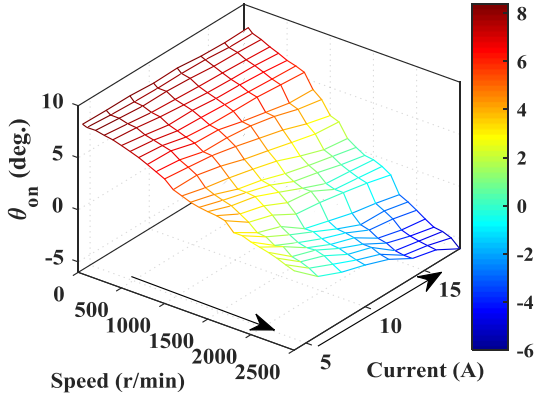

(a) Switch-on angles

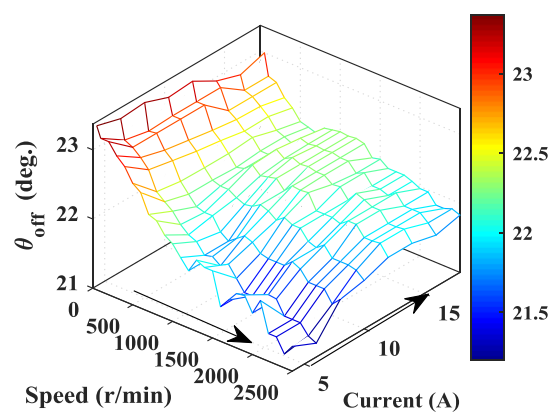

(b) Switch-off angles

Figure 5

Lookup tables of optimized switching angles

These MSACA-optimized switching angles are stored in lookup tables and adopted as inputs to the Simulink model of the SRM, and the corresponding Simulink results are presented in the next section.

\section{Simulation Results and Discussion}

In order to show the feasibility and effectiveness of the proposed control method, a comparison with the literature is achieved. Ref [20] is chosen for the comparison because it focuses mainly on reducing torque ripple and copper losses. The results involve steady-state and dynamic comparisons as follows.

\subsection{The Steady-State Performance}

Figures 6 (b), 7 (b), and 8 (b) show the obtained steady-state current and torque waveforms when applying MSACA-optimized switching angles to the Simulink model in Figure 2 at a speed of $700 \mathrm{r} / \mathrm{min}, 1500 \mathrm{r} / \mathrm{min}$, and $2400 \mathrm{r} / \mathrm{min}$, respectively. While, Figures 6 (a), 7 (a), and 8 (a) give the corresponding results when applying a switch-on angle that forces an intersection between the last peak of the outgoing phase current and the first peak of the incoming phase current [20]. As noted, the proposed method has a better torque profile with minimum torque ripples. 

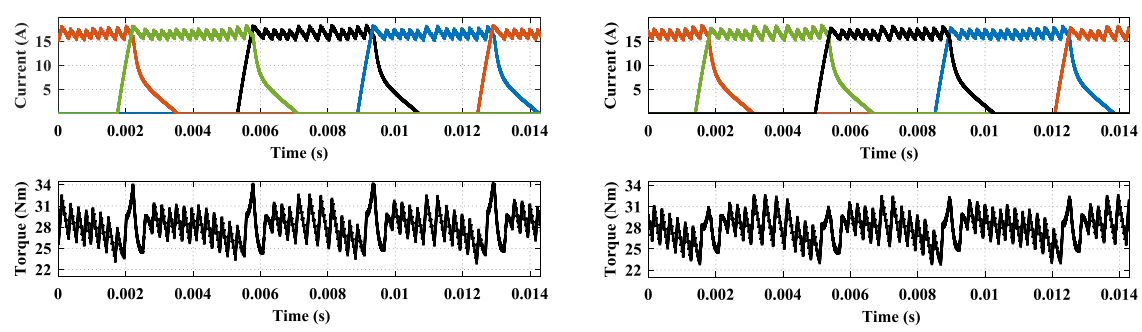

(a) Ref [20]

(b) The proposed

Figure 6

Steady-state simulation results for $700 \mathrm{r} / \mathrm{min}$ speed and $16 \mathrm{~A}$ commanded current
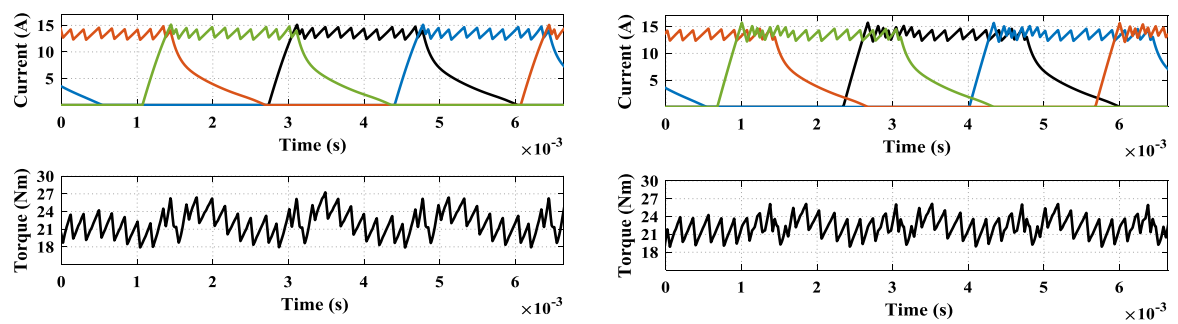

(a) Ref [20]

(b) The proposed

Figure 7

Steady-state simulation results for $1500 \mathrm{r} / \mathrm{min}$ speed and $14 \mathrm{~A}$ commanded current

The detailed analysis of steady-state results is given in Table 3. As seen in the table, for the same speed and the same reference current, both methods have almost the same average torque and a comparable value of efficiency. The proposed method has a significant reduction in torque ripple. However, it possesses a bit lower efficiency. However, it shows the best overall performance.
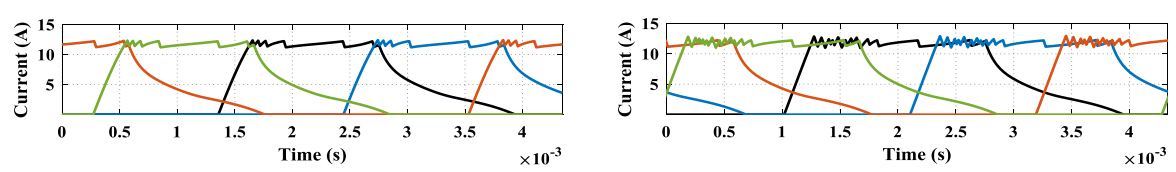

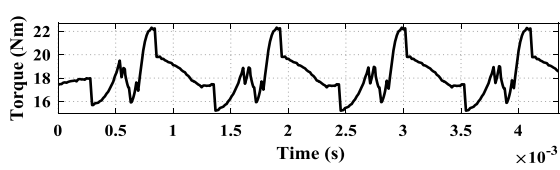

(a) $\operatorname{Ref}[20]$

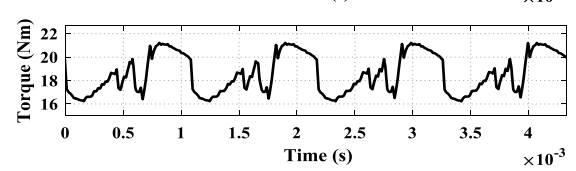

(b) The proposed

Figure 8

Steady-state simulation results for $2400 \mathrm{r} / \mathrm{min}$ speed and $12 \mathrm{~A}$ commanded current 
Table 3

Optimized parameters

\begin{tabular}{|c|c|c|c|c|c|c|}
\hline Algorithm & $\omega(\mathrm{r} / \mathrm{min})$ & $i_{r e f}(A)$ & $\theta_{\text {on }} / \theta_{\text {off }}\left({ }^{\circ}\right)$ & $T_{a v}(\mathrm{Nm})$ & $T_{r i p}(\%)$ & $\eta(\%)$ \\
\hline Ref [20] & \multirow{2}{*}{700} & \multirow{2}{*}{16} & $5.31 / 22.1$ & 28.13 & 40.3 & 92.3 \\
\hline Proposed & & & $5.69 / 22.1$ & 28.01 & 35.1 & 93.2 \\
\hline Ref [20] & \multirow{2}{*}{1500} & \multirow{2}{*}{14} & $3.62 / 21.95$ & 21.9 & 40.7 & 96.2 \\
\hline Proposed & & & $0.11 / 21.95$ & 22.35 & 31.5 & 95.5 \\
\hline Ref [20] & \multirow{2}{*}{2400} & \multirow{2}{*}{12} & $2.58 / 21.77$ & 18.2 & 38.17 & 97.4 \\
\hline Proposed & & & $-2.1 / 21.77$ & 18.6 & 27.23 & 96.8 \\
\hline
\end{tabular}

\subsection{The Dynamic Performance}

For the dynamic performance investigation, the results (in Figure 5) are implemented within the proposed closed-loop speed controller of SRM, as shown in Figure 9.

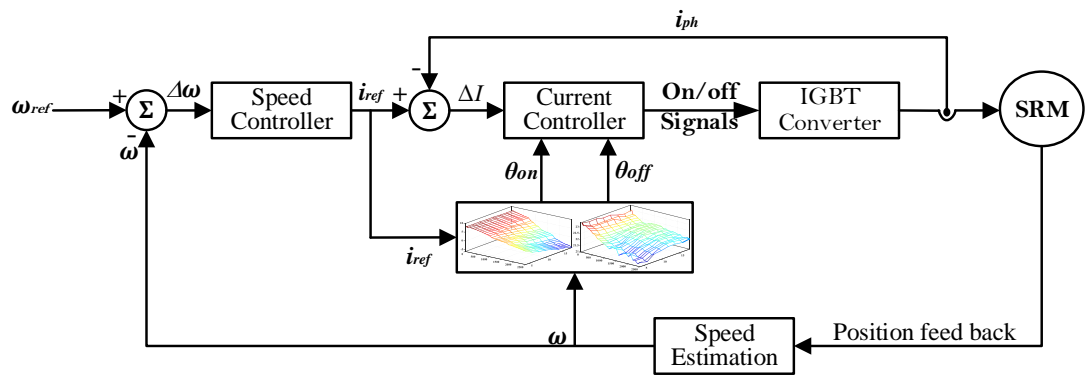

Figure 9

Overview of the proposed closed-loop speed controller for 8/6 SRM

Figure 10 shows the dynamic torque waveform and the variations of the switching angle at constant load torque of $20 \mathrm{Nm}$ and different speeds. It can be seen that the dynamic torque performance in Figure 10 (d) is much superior to in Figure 10 (c), especially at transit conditions. This is because in [20], the switch-on angle is tuned online using a PI controller, and therefore, this controller will require a certain time period before it achieves the final value of the switch-on angle. This delay will badly affect the dynamic performance during transit periods.

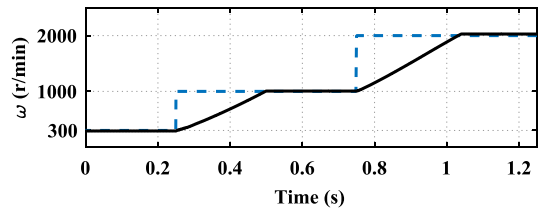

(a)

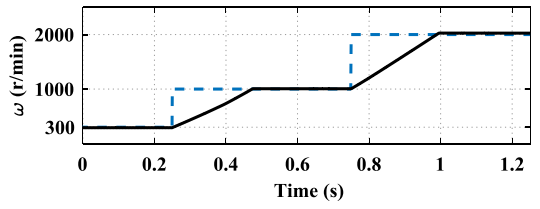

(b) 


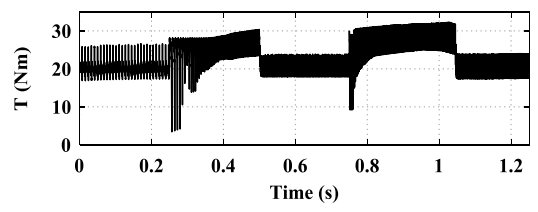

(c)

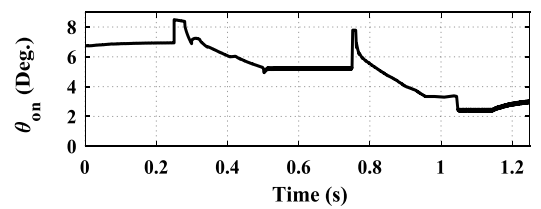

(e)

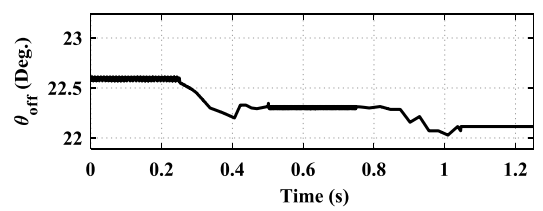

(g)

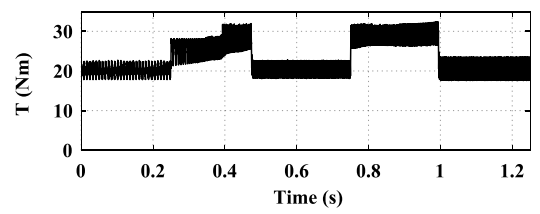

(d)

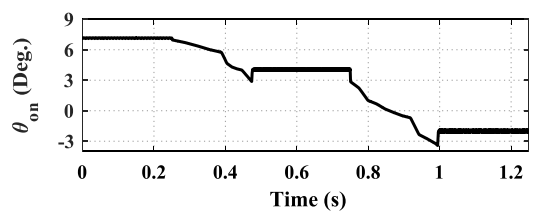

(f)

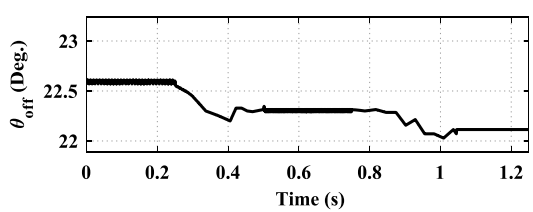

(h)

Figure 10

The dynamic performance at constant load torque of $20 \mathrm{Nm}$ and different speeds

Figure 11 shows the dynamic torque waveform and the variations of the switching angle when the motor runs at a constant speed $(1200 \mathrm{r} / \mathrm{min})$ and subjects to a sudden loading torque of $20 \mathrm{Nm}$ at $0.1 \mathrm{sec}$, as seen in Figure 11 (c, b). As noted, the proposed method has better torque dynamics with a better profile and reduced ripple, especially at transient moments. Besides, the variation of switching angles is shown in Figure 11(e, f). It is observed that the proposed control changes the switching angles instantaneously according to the operating point.

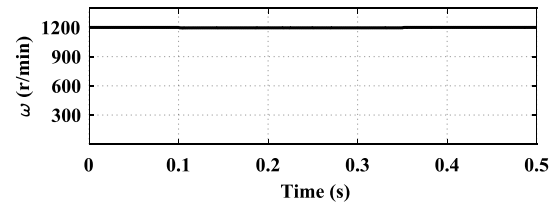

(a)

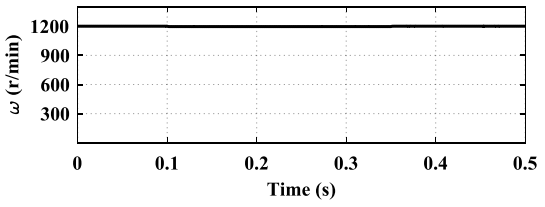

(b) 


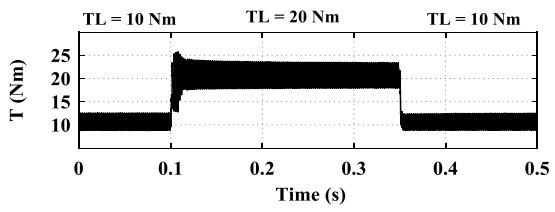

(c)

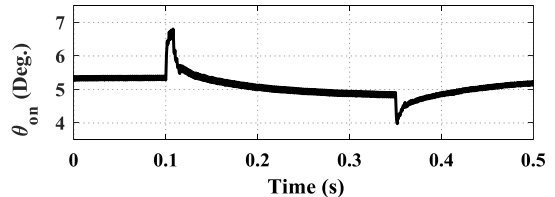

(e)

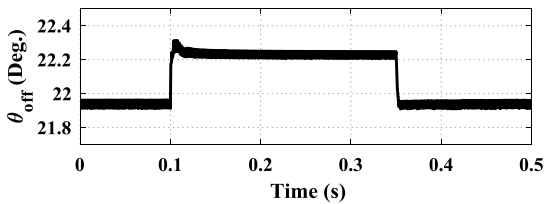

$(\mathrm{g})$

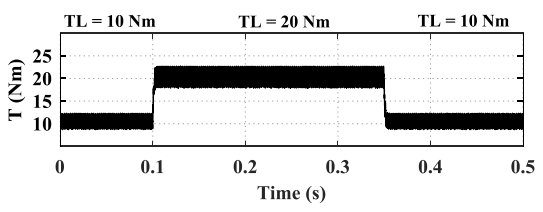

(d)

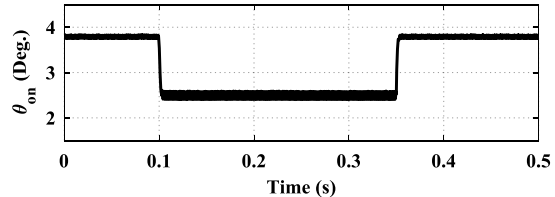

(f)

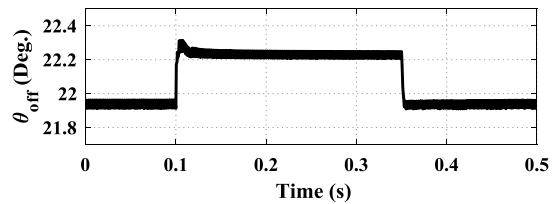

(h)

Figure 11

The dynamic performance at $1200 \mathrm{r} / \mathrm{min}$ when the motor is subjected to a load torque disturbance from $10 \mathrm{Nm}$ to $20 \mathrm{Nm}$ to $10 \mathrm{Nm}$

\section{Experimental Verification}

The experimental test-bed is shown in Figure 12 is constructed to validate the theoretical findings. The SRM is coupled mechanically with an electromagnetic brake. The drive system involves an IGBT asymmetrical bridge converter, current transducers, TMS320F28335 control board, 1024 PPR incremental encoder, data acquisition board (DAQ NI USB-6009). 


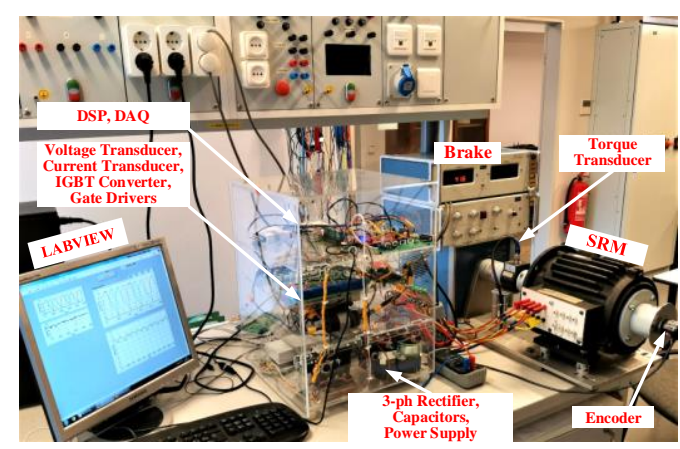

Figure 12

The experimental testbed

\subsection{Model Verification}

The accuracy of FEM-calculate results has been previously verified in Figure 1. However, for more demonstrations, the accuracy of the dynamic simulation model is verified here in Figure 13. In this figure, a comparison between the simulated motor waveforms and the experimentally measured ones is given. The comparison involves the dynamic waveforms for phases' current and total electromagnetic torque. An excellent agreement is observed that reflects the model accuracy.

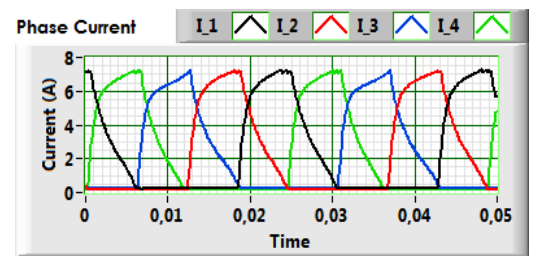

(a) Measured phase current

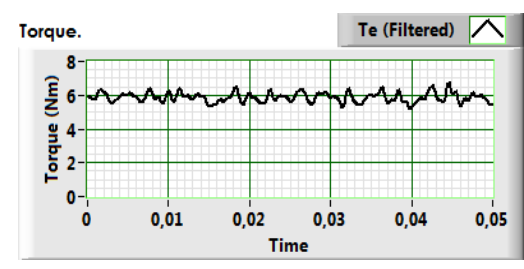

(c) Measured torque waveform

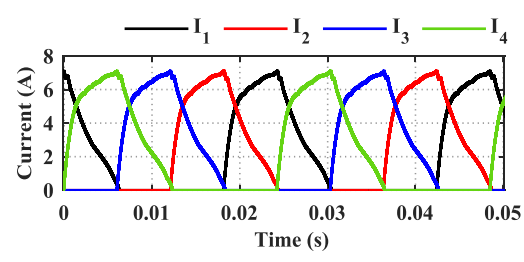

(b) Simulated phase current

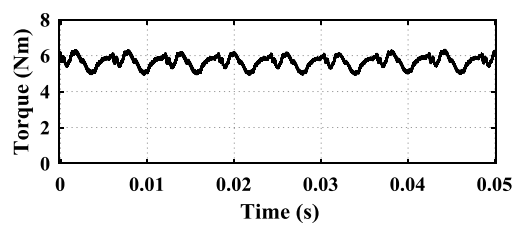

(b) Simulated torque waveform

Figure 13

Comparison between the measured and simulated current and torque curves at a speed of $410 \mathrm{r} / \mathrm{min}$ and $7 \mathrm{~A}$ commanded current 


\subsection{Experimental Comparative Analysis}

Figures 14 and 15 show a quantitative comparison between the proposed control method and Ref. [20]. Figures 14 give the comparison under the low speed of 360 $\mathrm{r} / \mathrm{min}$. As noted, the proposed MSACA shows the best torque profile. It also draws a lower supply current and hence lower copper losses. The detailed quantitative analysis is seen in Table 4 . The proposed MSACA has the lowest torque ripple of $29.8 \%$ compared to $40.3 \%$ for Ref. [20]. Besides, the proposed MSACA provides the best efficiency and the higher torque to current ratio.

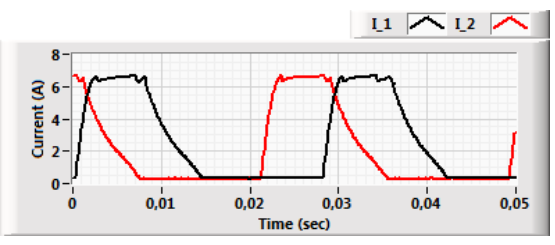

(a) Current waveforms of Ref. [20]

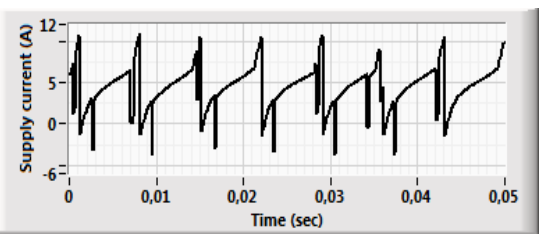

(c) Supply current waveform of Ref. [20]

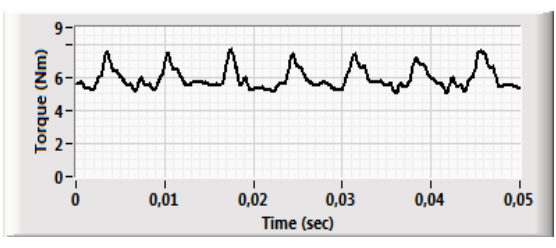

(e) Torque waveform of Ref. [20]

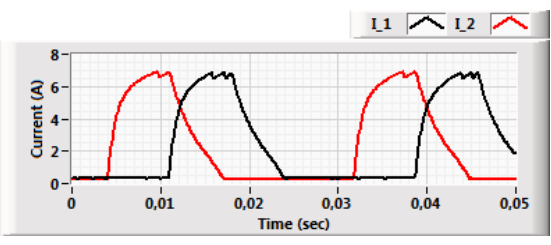

(b) Current waveforms of MSACA

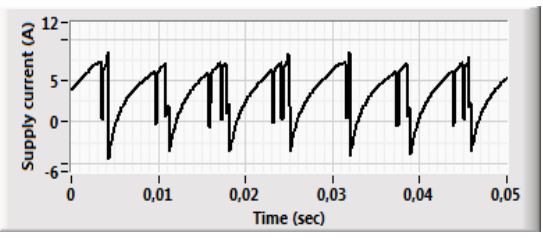

(d) Supply current waveform of MSACA

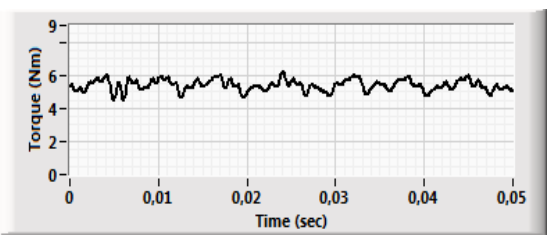

(f) Torque waveform of MSACA

Figure 14

Experimental results for $360 \mathrm{rpm}$ speed and $5.6 \mathrm{Nm}$ load torque

Figures 15 give the comparison under a higher speed of $570 \mathrm{r} / \mathrm{min}$. As noted, the proposed MSACA shows the best torque profile. The proposed MSACA has the lowest torque ripple of $25.5 \%$ compared to $50.1 \%$ for Ref. [20]. Besides, the proposed MSACA provides the highest torque to current ratio. However, it possesses a bit lower efficiency. 


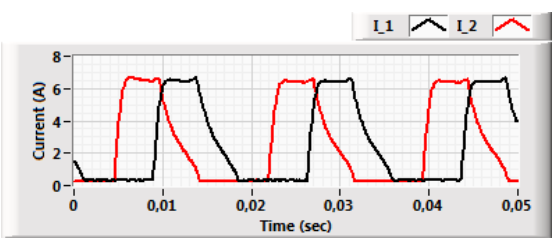

(a) Current waveforms of Ref. [20]

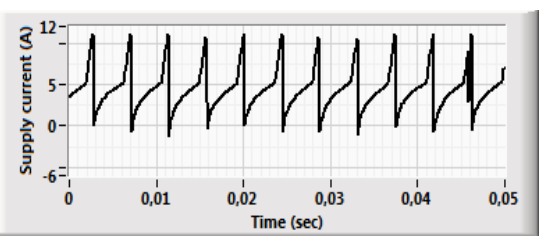

(c) Supply current waveform of Ref. [20]

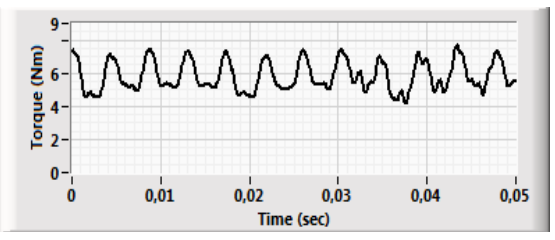

(e) Torque waveform of Ref. [20]

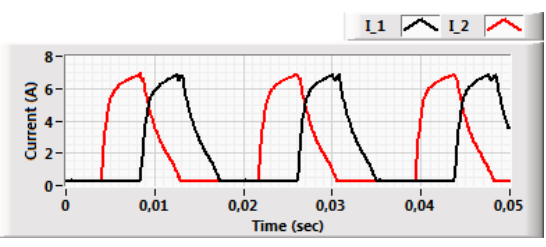

(b) Current waveforms of MSACA

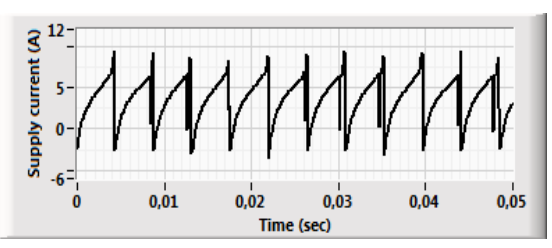

(d) Supply current waveform of MSACA

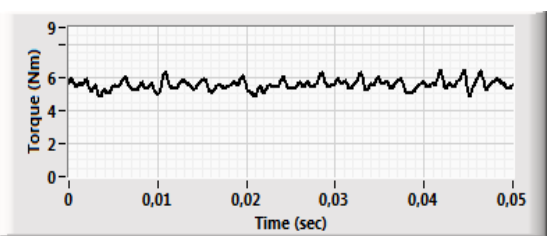

(f) Torque waveform of MSACA

Figure 15

Experimental results for $570 \mathrm{rpm}$ speed and 5.4 Nm load torque

Table 4

A comparison between Ref. [20] and MSACA parameters

\begin{tabular}{|l|c|c|c|c|c|c|}
\hline Algorithm & \multirow{2}{*}{$\begin{array}{c}\text { Speed } \\
(\mathrm{r} / \mathrm{min})\end{array}$} & $\begin{array}{c}i_{\text {ref }} \\
(\mathrm{A})\end{array}$ & $\begin{array}{c}\theta_{\text {on }} / \theta_{\text {off }} \\
(\text { Degree })\end{array}$ & $\begin{array}{c}T_{\text {ave }} / I_{\text {RMS }} \\
(\mathrm{Nm} / \mathrm{A})\end{array}$ & $\begin{array}{c}T_{\text {ripple }} \\
(\%)\end{array}$ & $\eta(\%)$ \\
\cline { 1 - 5 } Ref. [20] & \multirow{2}{*}{360} & \multirow{2}{*}{6.3} & $5.6 / 22.5$ & 1.07 & 40.3 & 65.1 \\
\cline { 1 - 4 } MSACA & & & $7.7 / 23.5$ & 1.16 & 29.8 & 68.4 \\
\cline { 1 - 4 } Ref. [20] & \multirow{2}{*}{570} & \multirow{2}{*}{6.3} & $5.3 / 23.05$ & 1.245 & 50.1 & 79.2 \\
\cline { 1 - 4 } MSACA & & $6.8 / 23.05$ & 1.285 & 25.5 & 77.6 \\
\hline
\end{tabular}

\section{Conclusion}

This paper is an optimization-based method to provide the best overall performance of SRM. A trade-off is done to achieve the minimum torque ripple, the highest average torque, and the minimum losses. A multistage ACA (MSACA) is developed to fit properly with the high nonlinearity of SRM. The MSACA is employed to estimate the optimum switching angles over the entire torque-speed profile. The machine model is achieved accurately using FEM. Besides, the FEM-calculated characteristics are validated through a comparison with the measured ones. Moreover, the final dynamic simulation model is verified 
in a closed-loop control for the best validation. Both the simulation and the experimental results showed the effectiveness of the proposed MSACA based optimization problem. The proposed controller showed the lowest torque ripples and the highest torque to current ratio. It also gave the best efficiency under low speeds and a very good efficiency under high-speed ranges.

\section{References}

[1] B. Bilgin, J. W. Jiang, and A. Emadi: Switched Reluctance Motor Drives, CRC Press, 2019, pp. 1-794

[2] Z. Yueying, Y. Chuantian, Y. Yuan, W. Weiyan, and Z. Chengwen: Design and optimisation of an In-wheel switched reluctance motor for electric vehicles, Intelligent Transport Systems, 2019, Vol. 13, No. 1, pp. 175-182

[3] B. Anvari, H. A. Toliyat, and B. Fahimi: Simultaneous Optimization of Geometry and Firing Angles for In-Wheel Switched Reluctance Motor Drive, IEEE Transactions on Transportation Electrification, 2018, Vol. 4, No. 1, pp. 322-329

[4] R. Abdel-Fadil, F. Al-Amyal, and L. Szamel: Torque ripples minimization strategies of switched reluctance motor - A review, International IEEE Conference and Workshop in Óbuda on Electrical and Power Engineering (CANDO-EPE), Budapest, Hungary, 2019, pp. 41-46

[5] M. Hamouda and L. Szamel: Reduced torque ripple based on a simplified structure average torque control of switched reluctance motor for electric vehicles," International IEEE Conference and Workshop in Óbuda on Electrical and Power Engineering (CANDO-EPE), Budapest, Hungary, 2018, pp. 109-114

[6] H. Li, B. Bilgin, and A. Emadi: An Improved Torque Sharing Function for Torque Ripple Reduction in Switched Reluctance Machines, IEEE Transactions on Power Electronics, 2019, Vol. 34, No. 2, pp. 1635-1644

[7] M. Hamouda, Q. S. Ullah, and L. Szamel: Compensation of Switched Reluctance Motor Torque Ripple based on TSF Strategy for Electric Vehicle Applications, International Conference on Power Generation Systems and Renewable Energy Technologies (PGSRET), Islamabad, Pakistan, 2018, pp. 1-6

[8] R. M. Abdel-Fadil and L. Számel: Direct Instantaneous Torque Control of the Switched Reluctance Motor for Electric Vehicles Applications Using Fuzzy Logic Control, Acta Tech. Jaurinensis, 2019, Vol. 12, No. 2, pp. 101-116

[9] R. Abdel-Fadil and L. Számel: Predictive control of switched reluctance motors for aircraft electrical actuators applications, Acta Polytech. Hungarica, 2020, Vol. 17, No. 5, pp. 209-227

[10] M. Debouza, A. Al-Durra, H. M. Hasanien, S. Leng, and W. Taha: 
Optimization of switched reluctance motor drive firing angles using grey Wolf optimizer for torque ripples minimization, $44^{\text {th }}$ Annual Conference of the IEEE Industrial Electronics Society (IECON), Washington, DC, USA, 2018, pp. 619-624

[11] J. W. Jiang, B. Bilgin, and A. Emadi: Three-Phase 24/16 SwitchedReluctance Machine for a Hybrid Electric Powertrain, IEEE Transactions on Transportation Electrification, 2017, Vol. 3, No. 1, pp. 7685

[12] Z. Yueying, Y. Chuantian, and Z. Chengwen: Multi-Objective Optimization of Switched Reluctance Generator for Electric Vehicles, $21^{\text {st }}$ International Conference on Electrical Machines and Systems (ICEMS), Jeju, Korea (South), 2018, pp. 1903-1907

[13] M. Hamouda, A. Abdel Menaem, H. Rezk, M. N. Ibrahim, and L. Számel: Numerical Estimation of Switched Reluctance Motor Excitation Parameters Based on a Simplified Structure Average Torque Control Strategy for Electric Vehicles, Mathematics, 2020, Vol. 8, No. 8, p. 1213

[14] C. Mademlis and I. Kioskeridis: Performance optimization in switched reluctance motor drives with online commutation angle control, IEEE Transactions on Energy Conversion, 2003, Vol. 18, No. 3, pp. 448-457

[15] B. Blanqué, J. I. Perat, P. Andrada, and M. Torrent: Improving efficiency in switched reluctance motor drives with online control of turn-on and turn-off angles, European Conference on Power Electronics and Applications, Dresden, Germany, 2005, pp. 9 pp.-P. 9

[16] I. Kioskeridis and C. Mademlis: Maximum efficiency in single-pulse controlled switched reluctance motor drives, IEEE Transactions on Energy Conversion, Vol. 20, No. 4, pp. 809-817

[17] Y. Sozer and D. A. Torrey: Optimal turn-off angle control in the face of automatic turn-on angle control for switched-reluctance motors, IET Electric Power Applications, 2007, Vol. 1, No. 3, pp. 395-401

[18] X. Xue, K. Cheng, J. Lin, Z. Zhang, K. Luk, T. W. Ng, N. Cheung: Optimal control method of motoring operation for SRM drives in electric vehicles, IEEE Transactions on Vehicular Technology, 2010, Vol. 59, No. 3, pp. $1191-1204$

[19] Y. Z. Xu, R. Zhong, L. Chen, and S. L. Lu, "Analytical method to optimise turn-on angle and turn-off angle for switched reluctance motor drives, IET Electric Power Applications, 2012, Vol. 6, No. 9, pp. 593-603

[20] A. Shahabi, A. Rashidi, M. Afshoon, and S. M. Saghaian Nejad: Commutation angles adjustment in SRM drives to reduce torque ripple below the motor base speed, Turkish J. Electr. Eng. Comput. Sci., 2016, Vol. 24, No. 2, pp. 669-682 
[21] M. Hamouda and L. Számel: Optimum control parameters of switched reluctance motor for torque production improvement over the entire speed range, Acta Polytech. Hungarica, 2019, Vol. 16, No. 3, pp. 79-99

[22] S. S. Ahmad and G. Narayanan: Linearized Modeling of Switched Reluctance Motor for Closed-Loop Current Control, IEEE Transactions on Industry Applications, 2016, Vol. 52, No. 4, pp. 3146-3158

[23] W. Uddin and Y. Sozer: Analytical Modeling of Mutually Coupled Switched Reluctance Machines under Saturation Based on Design Geometry, IEEE Transactions on Industry Applications, 2017, Vol. 53, No. 5, pp. 4431-4440

[24] D. S. Mihic, M. V. Terzic, and S. N. Vukosavic: A New Nonlinear Analytical Model of the SRM with Included Multiphase Coupling, IEEE Transactions on Energy Conversion, 2017, Vol. 32, No. 4, pp. 1322-1334

[25] M. Hamouda and L. Számel: Accurate magnetic characterization based model development for switched reluctance machine, Period. Polytech. Electr. Eng. Comput. Sci., 2019, Vol. 63, No. 3, pp. 202-212

[26] Z. Abdmouleh, A. Gastli, L. Ben-Brahim, M. Haouari, and N. A. AlEmadi: Review of optimization techniques applied for the integration of distributed generation from renewable energy sources, Renewable Energy, 2017, Vol. 113, pp. 266-280

[27] J. Vaščák: Adaptation of fuzzy cognitive maps by migration algorithms, Kybernetes, 2012, Vol. 41, No. 3/4, pp. 429-443

[28] R. E. Precup, R. C. David, E. M. Petriu, A. I. Szedlak-Stinean, and C. A. Bojan-Dragos: Grey Wolf Optimizer-Based Approach to the Tuning of PiFuzzy Controllers with a Reduced Process Parametric Sensitivity, IFACPapersOnLine, 2016, Vol. 49, No. 5, pp. 55-60

[29] R. C. Roman, R. E. Precup, C. A. Bojan-Dragos, and A. I. Szedlak-Stinean: Combined Model-Free Adaptive Control with Fuzzy Component by Virtual Reference Feedback Tuning for Tower Crane Systems, Procedia Computer Science, 2019, Vol. 162, pp. 267-274

[30] H. Zapata, N. Perozo, W. Angulo, and J. Contreras: A Hybrid Swarm Algorithm for Collective Construction of 3D Structures, International Journal of Artificial Intelligence, 2020, Vol. 18, No. 1, pp. 1-18

[31] M. Moattari and M. H. Moradi: Conflict Monitoring Optimization Heuristic Inspired by Brain Fear and Conflict Systems, International Journal of Artificial Intelligence, 2020, Vol. 18, No. 1, pp. 45-62

[32] R.-E. Precup, R.-C. David, R.-C. Roman, E. M. Petriu, and A.-I. SzedlakStinean: Slime Mould Algorithm-Based Tuning of Cost-Effective Fuzzy Controllers for Servo Systems, International Journal of Computational Intelligence Systems, 2021, Vol. 14, No. 1, pp. 1042-1052 
[33] Marco Dorigo and Thomas Stützle, Ant Colony Optimization. The MITPress, 2004

[34] F. Al-Amyal, K. J. Al-Attabi, and A. Al-Khayyat: Multistage Ant Colony Algorithm for Economic Emission Dispatch Problem, International IEEE Conference and Workshop in Óbuda on Electrical and Power Engineering (CANDO-EPE), Budapest, Hungary, 2019, pp. 161-166 